\title{
Changes in mast cell infiltration: a possible mechanism in detrusor overactivity induced by visceral hypersensitivity
}

\author{
Nian-zhao Zhang ${ }^{1}$, Lin Ma ${ }^{1}$, Chen Jun ${ }^{1}$, Yan-xia Guo ${ }^{2}$, Hui-qing Yuan ${ }^{2}$ \\ ${ }^{1}$ Department of Urology, Qilu Hospital, Shandong University, Jinan, P.R. China; ${ }^{2}$ Department of \\ Biochemistry and Molecular Biology, Shandong University School of Medicine, Shandong University, \\ Jinan, P.R. China
}

\section{ABSTRACT}

Objective: To establish the detrusor overactivity (D0) model induced by visceral hypersensitivity (VH) and investigate the relationship between mast cell (MC) infiltration and DO.

Materials and Methods: Sixty rats are divided into 4 groups randomly: Group 1:Baseline group; Group 2: DO group; Group 3: CON group; Group 4: VH group. The colorectal distension (CRD) and abdominal withdral reflex (AWR) scores are performed to evaluate VH. The cystometric investigation and histological test of MC infiltration are assessed.

Results: The threshold pressure of CRD in the VH group is significantly lower than that in the CON group $(\mathrm{P}<0.001)$. At the distension pressure $\geq 20 \mathrm{mmHg}$, the AWR scores of the VH group are significantly higher than those of the CON group (10 mmHg: $\mathrm{P}=0.33$; 20 mmHg: $\mathrm{P}=0.028$; 40 mmHg: $\mathrm{P}<0.001 ; 60$ mmHg: $\mathrm{P}<0.001 ; 80 \mathrm{mmHg}: \mathrm{P}<0.001$ ). DO model is successfully established in the VH group (D0 rate $=100 \%$ ). Compared with the CON group, the numbers of MC infiltration are significantly increased in the $\mathrm{VH}$ group, including submucosa of bladder $(\mathrm{P}<0.001)$, mucosa lamina propria/mesentery of small intestine $(\mathrm{P}<0.001)$, and mucosa lamina propria/mesentery of large intestine $(\mathrm{P}<0.001)$. Furthermore, more MC activation as well as degranulation are observed in the VH group.

Conclusions: It is indicated that DO model can be established in the VH rats. The MC infiltration may play an important role in DO induced by $\mathrm{VH}$, and may be helpful to understand the mechanisms of DO in $\mathrm{VH}$ patients.

\section{ARTICLE INFO}

\section{Key words:}

Urinary Bladder, Overactive; Hypersensitivity; Mast-Cell

Sarcoma

Int Braz J Urol. 2016; 42: 373-82

Submitted for publication:

January 14, 2015

Accepted after revision:

August 02, 2015

\section{INTRODUCTION}

Overactive bladder syndrome $(\mathrm{OAB})$ is a symptom complex consisting of urinary urgency, usually accompanied by frequency and nocturia, with or without urinary incontinence. $\mathrm{OAB}$ is usually associated with involuntary contractions of the detrusor muscle, which can result in urge incontinence, depending on the response of the sphincter. The most common cause of $\mathrm{OAB}$ is de- trusor overactivity (D0) $(1,2)$. D0 is defined as the occurrence of involuntary detrusor contractions during filling cystometry. This diagnosis by symptoms and urodynamic investigations is made in patients with lower urinary tract symptoms when involuntary detrusor muscle contractions occur during filling cystometry $(1,3)$. Sixty-four percent of all patients with OAB have DO on cystometry, and $69 \%$ of men and $44 \%$ of women with urgency have DO (4). DO may occur in male patients with 
bladder outlet obstruction, which leads to several structural and functional changes in the detrusor muscle. On the other hand, DO is thought to result not only from efferent (motor) hyperfunction/dysfunction but also most likely by afferent (sensory) noise. However, the pathogenesis of DO currently is still unclear.

Visceral hypersensitivity (VH), a consistent finding in a large proportion of patients with irritable bowel syndrome (IBS), is currently considered a key pathophysiological mechanism involved in pain perception in large subgroups of patients with functional gastrointestinal disorders $(5,6)$. Furthermore, mast cell (MC) activation is thought to be involved in $\mathrm{VH}$, one of the main characteristics of IBS (7-10). Patients with IBS may have a disorder of smooth muscle or its innervation that is not confined to the gastrointestinal system (11, 12). Although IBS is marked by abdominal pain and alterations in bowel movement frequency or form, patients with this disorder may also experience urinary symptoms as DO, including frequency, urgency and dysuria (13). In a study of female patients, urinary urgency and frequency were significantly more common in those with IBS than in controls (14). The functional connection between the bladder and bowel, evidenced in studies of the neural crosstalk between these two organs, suggests that they may share some common underlying dysfunction (11, 15). However, the exact pathophysiology of DO in patients with IBS is not well-understood.

Although several epidemiological studies showed the association between the bladder and bowel $(11,12,15)$, less experimental work has been performed to study the relationship between DO and VH in the animal model. It is important and interesting to investigate the relationship between DO and VH, and the role of MC in DO model induced by VH. In our study, we established the DO model induced by VH to achieve a better understanding of MC in DO.

\section{MATERIALS AND METHODS}

Animals

Adult female Wistar rats (200-250g), obtained from the Experimental Animal Center of
Shandong University) were used in our study. The animals were housed under standardized conditions of temperature $\left(20 \pm 1^{\circ} \mathrm{C}\right)$, humidity $(50 \pm 5 \%)$ and lighting (12-h day/12-h night). All experimental procedures were performed at the same time of the day between 9:00am and 12:00am to avoid the effect of diurnal variations. This study was approved by Chinese Institutional Animal Care Committee and adhered to the ethical guidelines of the International Association for the Study of Pain. Great care was taken to minimize or avoid discomfort to the animals.

\section{Experimental treatments}

Sixty rats were divided into 4 groups randomly: Group 1: no intervention for establishing baseline values (Baseline group); Group 2: DO (without VH) induced by obstruction according to previous study (D0 group) [18]; Group 3: the control gave sodium chloride (CON group); Group 4: thirty milligrams chicken egg albumin (Sigma Co., USA, purity grade V) joined with $1 \mathrm{~mL}$ aluminum hydroxide gel with the mass concentration of $10 \mathrm{mg} / \mathrm{mL}$ (Sigma Co., USA), then mixed well before each rat accepted intraperitoneal injection according to previous study (VH group) (16). The colorectal distension (CRD) and abdominal withdrawal reflex (AWR) were performed to evaluate $\mathrm{VH}$, then the filling cystometry was performed to investigate the possibility of DO, and the relationship between DO and VH was evaluated. Lastly a light microscope was used to observe the MC infiltration of the bladder and intestine tissue stained by toluidine blue.

\section{Threshold pressure and AWR Scores (17)}

CRD in rats induces the contractions of abdominal and hind limb musculature, which has been validated as a quantitative measure of $\mathrm{VH}$. Behavioral responses to CRD were assessed by measuring the threshold pressure that induced the first abdominal contraction and the AWR with a scoring system.

Briefly, rats were lightly sedated with halothane while a flexible latex balloon $(4 \mathrm{~cm})$ made of a surgical glove finger attached to a Tygon tubing with thread was inserted intra-anally into the descending colon and rectum until the thread end 
was $1 \mathrm{~cm}$ proximal to the anal sphincter. And the balloon was secured in place by taping the tubing to the tail. Rats were then placed in small Lucite cubicles $(20 \times 8 \times 8 \mathrm{~cm})$ and allowed $30 \mathrm{~min}$ for recovery from sedation before testing. For measuring the threshold pressure of CRD, the colorectal balloon was progressively inflated with an increment of $5 \mathrm{mmHg}$ until the pain behavior displayed or until a cutoff pressure of $80 \mathrm{mmHg}$ was reached in order to avoid invincible damage to the rat. For measuring the AWR, the balloon was rapidly inflated to constant pressure $[10,20,40$, $60,80 \mathrm{mmHg}]$. The AWR scores were graded on a scale of 0 to 4: 0: no behavioral response to CRD; 1: brief head movement followed by immobility; 2: contraction of abdominal muscles; 3 : lifting of abdomen; 4: body arching and lifting of pelvic structures. For the both measurements (threshold pressure and AWR), the animals were given CRD with 30-s duration and then 4-min interval. All the measurements were assessed by two blinded observers in triplicate.

\section{URODYNAMIC AND HISTOLOGICAL TEST}

\section{Urodynamic test}

In the cystometric investigation, the conscious rats were held under partial restraint in a restraining device (18). The bladder was catheterized through urethra by a human epidural catheter (F2, 0.7-mm outer diameter, 0.4-mm internal diameter), which was connected via a T-tube to urodynamic testing machine (Laborie medical technologies, Corp) and infusion pump (LION WZ-50C6 microinfusion pump, Zhejiang University, China).

The rats were placed supine and the urethral orifice could be observed clearly. Data were collected and analyzed after the animals were seen to be resting quietly in the restraining device. The cystometric investigation was performed by infusing warm saline $\left(37-38^{\circ} \mathrm{C}\right)$ at a rate of $9 \mathrm{~mL} / \mathrm{h}$, and the infusion was stopped when voiding contraction was observed according to the voiding pressure and the leakage of urine around the urethral orifice. Bladder emptying was ascertained by opening the catheter and gently pressing the lower abdomen after the cystometry. During the filling phase, some of the rats had obvious non-voiding contractions before the onset of voiding contraction and thus were defined as having DO (19). According to the previous study (18), three urodynamic cycles per animal were recorded to insure reproducibility of the bladder responses.

\section{Histological test of MC}

After urodynamic test and micturition for thirty minutes, each rat was successfully anesthetized (10\% chloral hydrate, $3 \mathrm{~mL} / \mathrm{kg}$, i.p.). In each rat, a median incision of the abdomen was chosen to expose the organs, and the bladder and intestine were quickly removed. Histological changes in the bladder and intestine tissue were observed by the stained by toluidine blue to research MC. The numbers of MC were counted in 5 consecutive fields $(\times 400)$, and the mean values were used in the subsequent statistical analysis. The urodynamic and histological test were assessed by two blinded observers in triplicate.

\section{Statistical analysis}

The model data were expressed as mean \pm standard deviation (SD), and SPSS 16.0 statistical software (SPSS Inc., IL, USA) was used to conduct the $t$ test. $\mathrm{P}$ value $<0.05$ was considered statistically significant.

\section{RESULTS}

\section{Threshold Pressure of CRD}

The threshold pressure to elicit a distinctive abdominal muscle contraction in response to CRD was recorded in the 4 groups, respectively. Compared with the CON group, the visceral responses of the $\mathrm{VH}$ group to CRD were significantly greater. The results showed that the threshold pressure of CRD in the VH group was significantly lower than that in the CON group $(22 \pm 3.4 \mathrm{mmHg}$ versus $29 \pm 6.1 \mathrm{mmHg}, \mathrm{P}<0.001$, Figure-1).

\section{AWR Scores}

A series of graded responses were shown in the 4 groups with the balloon pressure increasing from 10 to $80 \mathrm{mmHg}$. At the distension pressure $10 \mathrm{mmHg}$, the mean AWR scores in the VH group 
Figure 1 - Comparison of threshold pressure in response to CRD between CON and VH group $(29 \pm 6.1$ versus $22 \pm 3.4$, $\left.{ }^{* * *} \mathrm{P}<0.001\right)$.

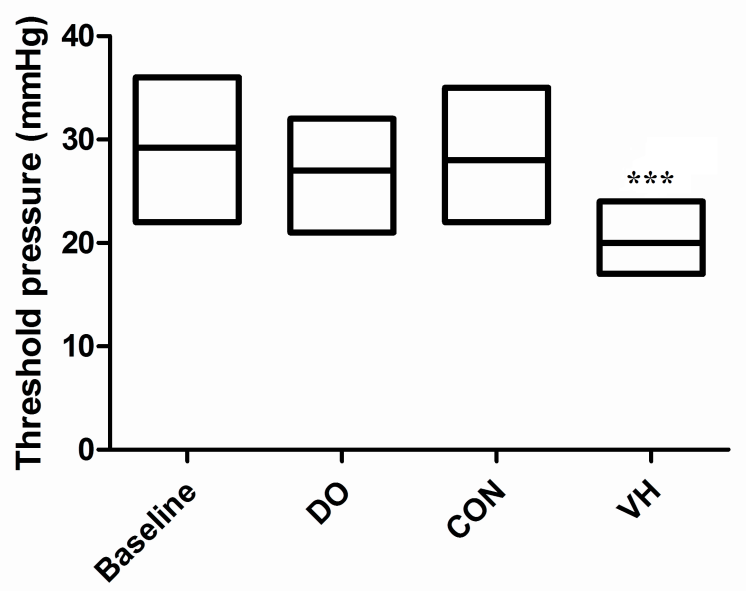

approximated to those in the CON group. At the distension pressure $\geq 20 \mathrm{mmHg}$, the rats in the $\mathrm{VH}$ group exhibited stronger responses than those in the CON group as reflected by significantly higher AWR scores (10mmHg: $1.0 \pm 0.13$ versus $0.87 \pm 0.12$, $\mathrm{P}=0.33$; $20 \mathrm{mmHg}$ : $1.7 \pm 0.20$ versus $1.3 \pm 0.22$, $\mathrm{P}=0.028$; 40mmHg: $3.0 \pm 0.27$ versus $2.2 \pm 0.29$, $\mathrm{P}<0.001 ; 60 \mathrm{mmHg}$ : $3.5 \pm 0.38$ versus $2.7 \pm 0.22, \mathrm{P}$ $<0.001$; 80mmHg: $3.9 \pm 0.062$ versus $3.2 \pm 0.16, \mathrm{P}$ $<0.001$; Figure-2).

Figure 2 - Comparison of AWR scores between CON and VH group. $(10 \mathrm{mmHg}$ : $0.87 \pm 0.12$ versus $1.0 \pm 0.13, P=0.33$; $20 \mathrm{mmHg}$ : $1.3 \pm 0.22$ versus $1.7 \pm 0.20,{ }^{*} \mathrm{P}=0.028$; $40 \mathrm{mmHg}$ : $2.2 \pm 0.29$ versus $3.0 \pm 0.27,{ }^{* * *} \mathrm{P}<0.001 ; 60 \mathrm{mmHg}: 2.7 \pm 0.22$ versus $3.5 \pm 0.38,{ }^{* *}{ }^{*} P<0.001 ; 80 \mathrm{mmHg}: 3.2 \pm 0.16$ versus $\left.3.9 \pm 0.062,{ }^{* *} P<0.001\right)$.

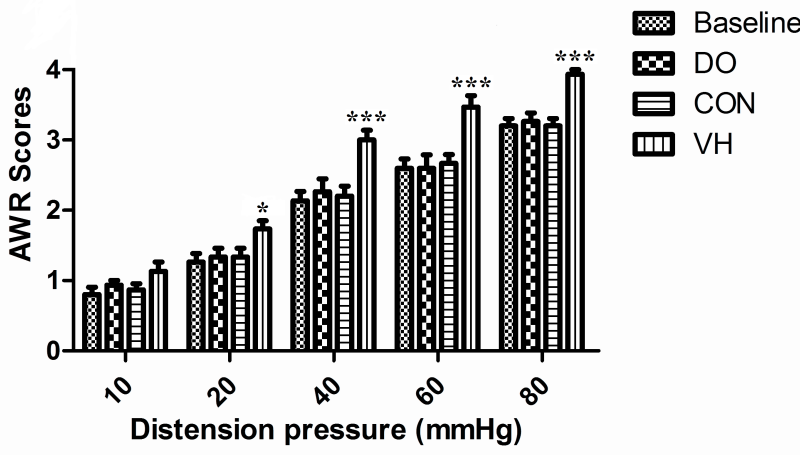

Urodynamic and histological test of MC

Cystometric investigation was performed in the 4 groups. In the CON group, the bladder filling status was at a low pressure during urine storage, and the detrusor contraction pressure increased significantly during urination and returned to normal status after urination (D0 rate $=0 \%$, Figure-3C), while the VH group had obvious non-voiding contractions before the onset of voiding contraction and thus was defined as having D0 (D0 rate $=100 \%$, Figure-3D). The peak voiding pressure of the VH group is higher than the CON group $\left(62.5 \pm 5.4 \mathrm{~cm} . \mathrm{H}_{2} \mathrm{O}\right.$ versus $50.3 \pm 3.7 \mathrm{~cm} \cdot \mathrm{H}_{2} \mathrm{O}$, $\mathrm{P}=0.024$, Table- 1 ).

We harvested the bladder and intestine tissue for subsequent histological assessment in the 4 groups. Compared with the CON group, the numbers of MC infiltration were significantly increased in the $\mathrm{VH}$ group, including submucosa of bladder $(1.6 \pm 1.4$ versus $8.3 \pm 6.6, \mathrm{P}<0.001$, Figure-4), mucosa lamina propria/mesentery of small intestine $(0.67 \pm 0.49$ versus $4.2 \pm 2.8, \mathrm{P}<0.001, \mathrm{Fi}-$ gure-5), and mucosa lamina propria/mesentery of large intestine $(1.6 \pm 0.77$ versus $6.5 \pm 5.0, P<0.001$, Figure-6). Furthermore, more MC activation as well as degranulation showed the pathological changes in the submucosa of bladder and mucosa lamina propria/mesentery of intestine in the $\mathrm{VH}$ rats (Figures 7-9).

\section{DISCUSSION}

We established a model of DO in VH rats. Our results confirmed that the $\mathrm{VH}$ rats presented altered voiding patterns, and non-voiding contractions occurring prior to voiding were observed in the VH rats. Following voiding, no involuntary detrusor contraction was recorded but the involuntary detrusor contractions developed slowly with increasing amplitude until the next voiding occurred. Interestingly, the DO pattern observed in our study was characterized by an increased involuntary detrusor contractions during the filling phase, which was in agreement with findings in patients showing D0 associated with an increase in voiding pressure (20). Therefore, the DO model induced by VH established in our study was consistent with the clinical characteristics of DO patients. 
Figure 3 - The cystometric investigation of the 4 groups (one voiding contraction is observed and the number indicates peak voiding pressure).
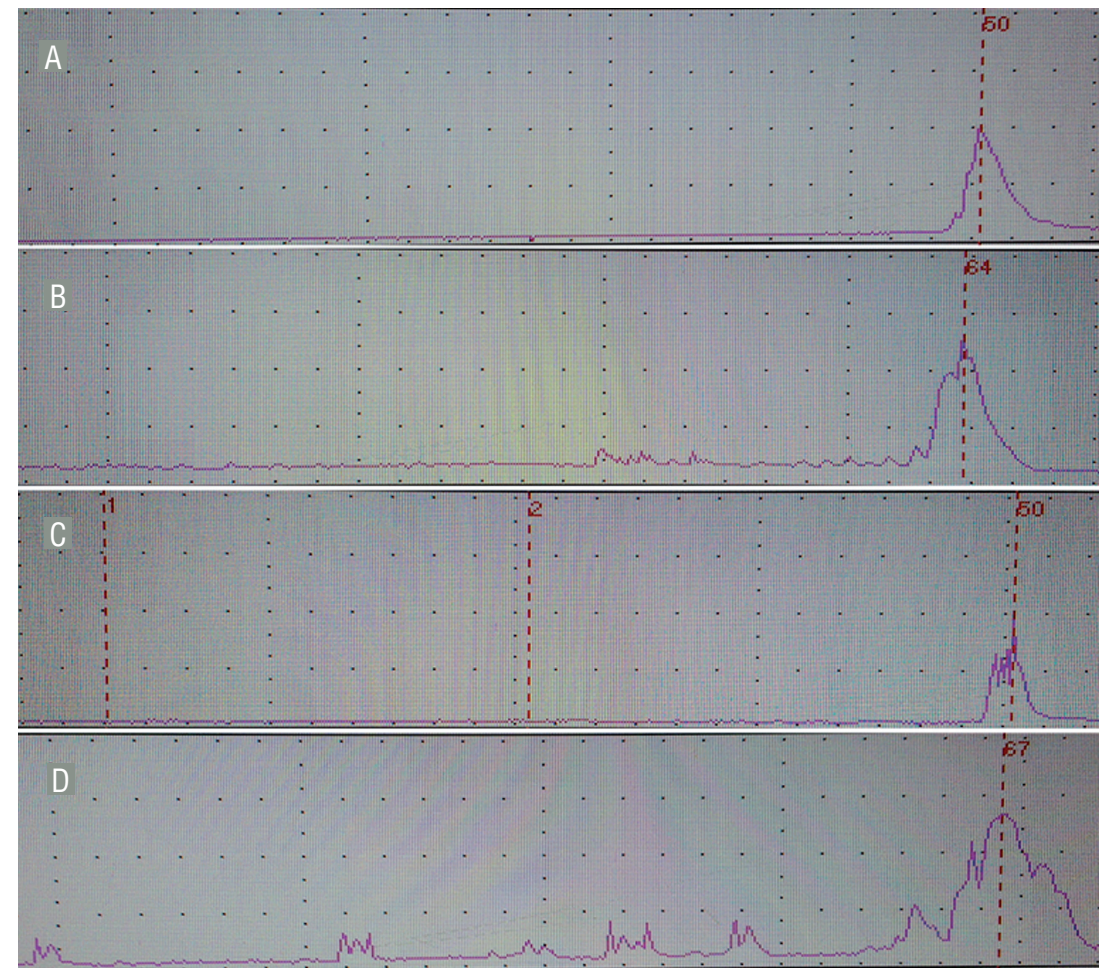

A) Baseline; B) D0; C) CON; D) VH.

Table 1 - Comparison of cystometric investigation between CON and VH group (Mean $\pm S D$ ).

\begin{tabular}{lcccc}
\hline Groups & $\mathrm{BC}(\mathrm{mL})$ & $\mathrm{P}$ & $\mathrm{VP}\left(\mathrm{cm} . \mathrm{H}_{2} \mathrm{O}\right)$ & $\mathrm{P}$ \\
\hline Baseline & $0.28 \pm 0.024$ & $0.217^{\mathrm{a}}$ & $47.8 \pm 3.3$ & \\
D0 & $0.79 \pm 0.16$ & & $67.9 \pm 12.8$ & \\
CON & $0.26 \pm 0.031$ & & $50.3 \pm 3.7$ & $0.024^{\mathrm{a}}$ \\
VH & $0.31 \pm 0.029$ & & $62.5 \pm 5.4$ & \\
\hline
\end{tabular}

$\mathbf{a}=$ CON versus $\mathrm{VH}$.

$\mathbf{B C}=$ Bladder capacity.

VP = Peak voiding pressure

VH has emerged as a key hypothesis in explaining the painful symptoms in IBS and has been proposed as a "biological hallmark" for the condition (21). Moreover, the functional connection between the bladder and bowel, evidenced in studies of the neural crosstalk between these two organs, suggests that they may share some common underlying dysfunction $(11,15)$. Thus VH, even including MC, may play an important role in the pathophysiological mechanism of DO.
The urinary bladder serves as reservoir that alternates between urine storage and efficient urine expulsion at a convenient moment (22). Normal bladder sensation is the basis to achieve urine storage and urination processes, all bladder neural reflexes and excitement transfers come from the transfer of bladder sensation. More evidence has shown that DO might be a cause of sensory nerve-mediated hypersensitivity or hyperactivity in addition to myogenic excitability (23). There 
Figure 4 - Comparison of MC infiltration of bladder between $\mathrm{CON}$ and VH group $\left(1.6 \pm 1.4\right.$ versus $\left.8.3 \pm 6.6,{ }^{* *} \mathrm{P}<0.001\right)$.
Figure 5 - Comparison of MC infiltration of small intestine between $\mathrm{CON}$ and $\mathrm{VH}$ group $(0.67 \pm 0.49$ versus $4.2 \pm 2.8$, $\left.{ }^{* * *} \mathrm{P}<0.001\right)$.
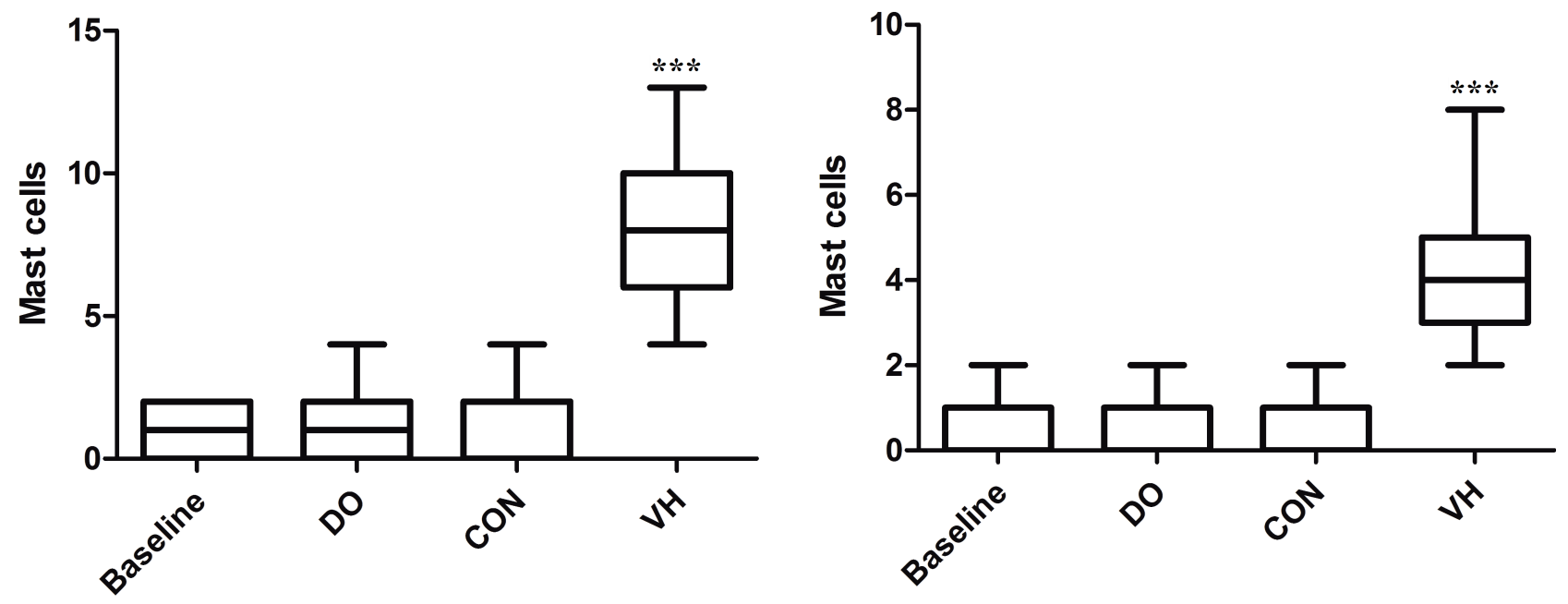

Figure 6 - Comparison of MC infiltration of large intestine between $\mathrm{CON}$ and VH group $(1.6 \pm 0.77$ versus $6.5 \pm 5.0$, $\left.{ }^{* * *} \mathrm{P}<0.001\right)$.

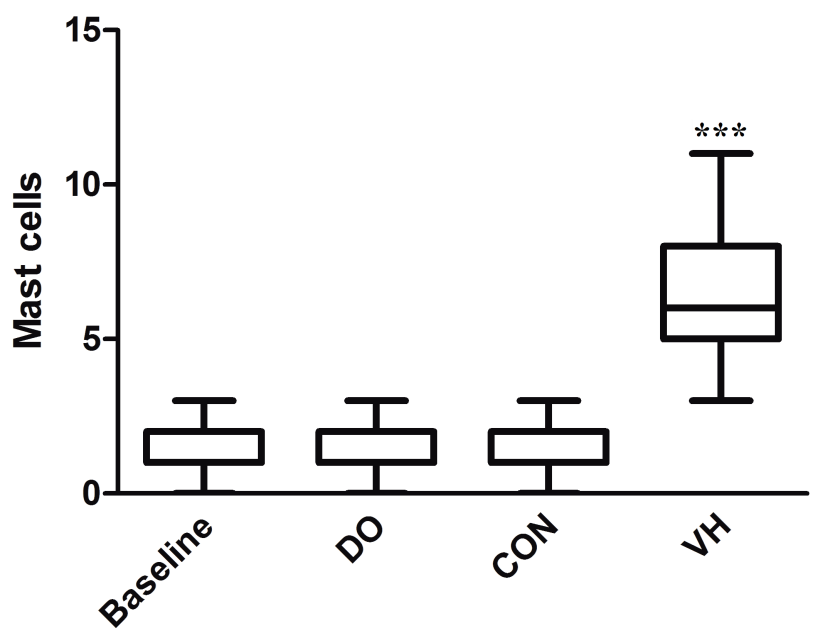

a close anatomic relationship between MC and bladder neuron, which has been demonstrated by electron microscopy (24). MC is found within nerves and intramural ganglia and is in close contact with individual nerve fibers. Close association between MC, nerves, and vessels is common, and ultrastructural evidence suggests that bidirectional communication occurs between MC and nerve fiber. These structures may participate in axon reflexes that regulate detrusor muscle function and cause bladder hyperreactivity (25).

The previous studies revealed that chronic inflammation, such as MC infiltration, was observed in patients with DO (26-29). MC is long-lived, tissue-resident cell that is enriched at boundaries of the body, where it may be especially numerous 
Figure 7 - The MC infiltration of bladder in the 4 groups $(\times 400)$

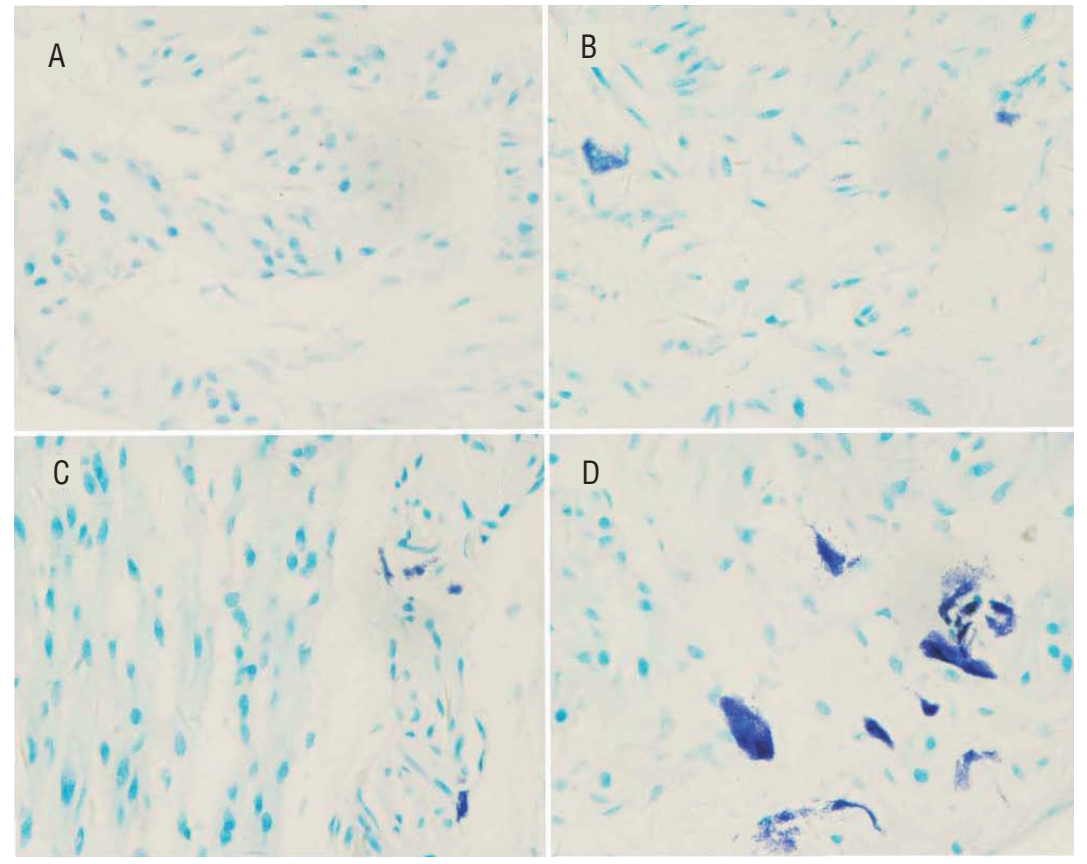

A) Baseline; B) DO; C) CON; D) VH.

Figure 8 - The MC infiltration of small intestine in the 4 groups $(\times 400)$.

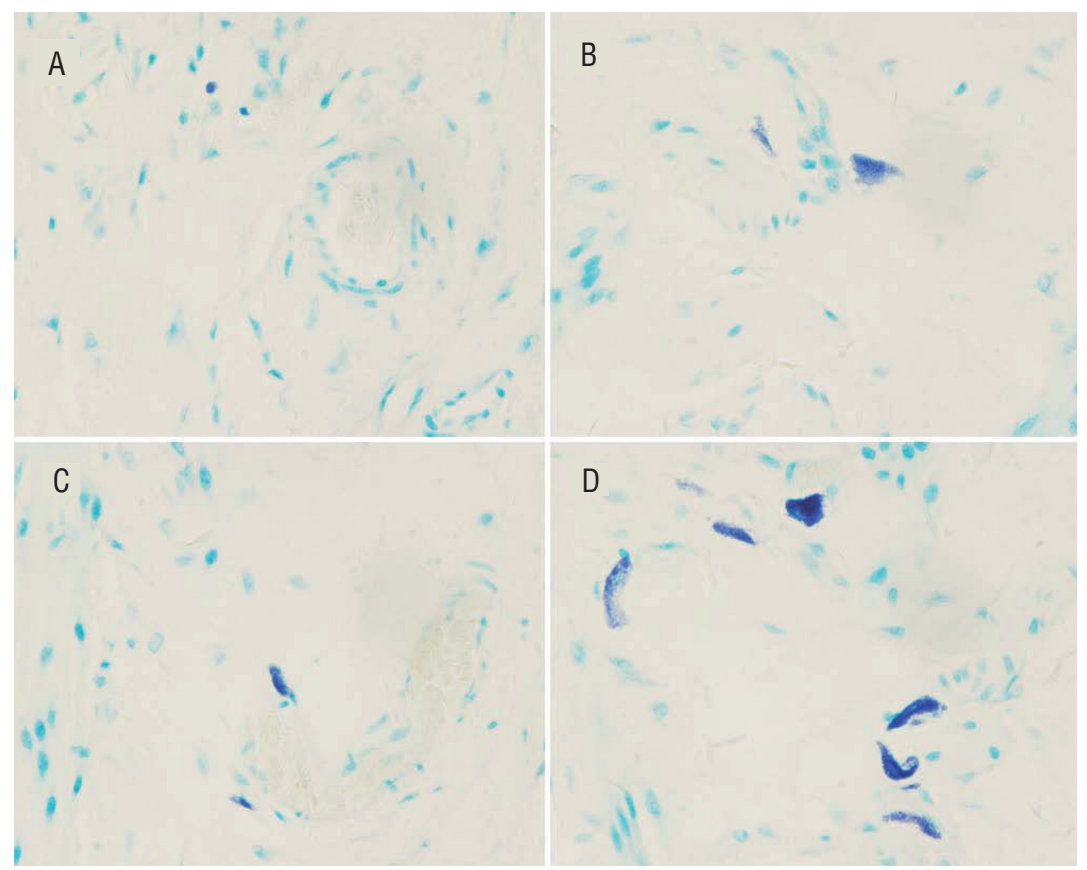

A) Baseline; B) D0; C) CON; D) VH. 
Figure 9 - The MC infiltration of large intestine in the 4 groups $(\times 400)$.

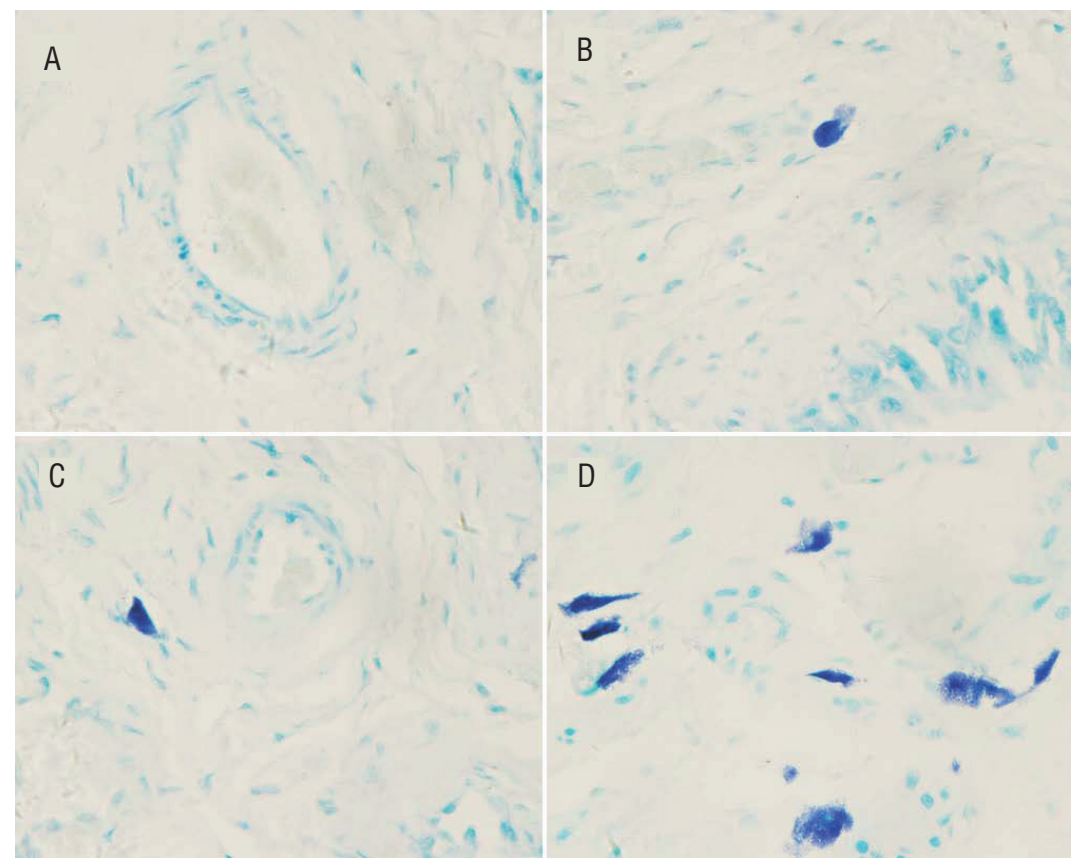

A) Baseline; B) DO; C) CON; D) VH.

in the gastrointestinal and genitourinary tracts, adjacent to blood or lymphatic vessels, and near or within peripheral nerves (30). MC mediators are granule-stored, presynthesized molecules or are synthesized de novo (31). MC may be activated by a number of mechanisms within the urinary bladder. Evidence has shown that the urothelium could release a number of neuropeptides (eg, nerve growth factor [NGF]) and neurotransmitters that may activate submucosal afferent nerve and MC (32, 33). These changes in urothelial permeability, urothelial activation, sensory nerve stimulation, and MC activation are complex and highly interrelated with multiple and simultaneous positive and negative feedback loops.

Recent study has shown that MC involved in the inflammatory response to the pathogenesis of $\mathrm{OAB}$, which was frequently associated with DO (29). One pathogeneses, which have been proposed for DO, is the interaction of MC with nerve cell to produce neurogenic inflammation. Patients with DO have been found to have increased urinary NGF level $(27,28)$. NGF might act as a mediator for bidirectional communication between muscle or urothelium and nerve fibers, including primary sensory afferents (23). The level of NGF in urine could cause DO through some pathways, and it was suggested that MC, the NGF producer, was involved in the pathway of the pathogenesis of DO (29).

In this study, DO model is successfully established in the VH rats, and the common underlying dysfunction between the bladder and bowel is evidenced. Importantly, it is indicated that MC may play an important role in DO. However, our study has several weaknesses. Although our model demonstrated the association between $\mathrm{DO}$ and $\mathrm{VH}$, the systematic pathophysiology of DO induced by VH remains unclear. Secondly, our study in animal indicated abnormality of MC infiltration in D0, but the underlying mechanisms can not be confirmed in the absence of further clinical studies to clarify the details. 


\section{CONCLUSIONS}

In conclusion, it is indicated that DO model can be established in VH rats. The MC infiltration may play an important role in $\mathrm{DO}$ induced by $\mathrm{VH}$, and may be helpful to understand the mechanisms of DO in VH patients.

\section{CONFLICTS OF INTEREST}

None declared.

\section{REFERENCES}

1. Abrams P, Cardozo L, Fall M, Griffiths D, Rosier P, Ulmsten $\mathrm{U}$, et al. Standardisation Sub-committee of the International Continence Society. The standardisation of terminology of lower urinary tract function: report from the Standardisation Sub-committee of the International Continence Society. Neurourol Urodyn. 2002;21:167-78.

2. Al-Ghazo MA, Ghalayini IF, Al-Azab R, Hani OB, Matani YS, Haddad Y. Urodynamic detrusor overactivity in patients with overactive bladder symptoms. Int Neurourol J. 2011;15:48-54.

3. Haylen BT, de Ridder D, Freeman RM, Swift SE, Berghmans $\mathrm{B}$, Lee $\mathrm{J}$, et al. InternationalUrogynecological Association; International Continence Society. An International Urogynecological Association (IUGA)/International Continence Society (ICS) joint report on the terminology for female pelvic floor dysfunction. Neurourol Urodyn. 2010;29:4-20.

4. Abrams P, Andersson KE. Muscarinic receptor antagonists for overactive bladder. BJU Int. 2007;100:987-1006.

5. Barbara G, Cremon C, De Giorgio R, Dothel G, Zecchi $L$, Bellacosa L, et al. Mechanisms underlying visceral hypersensitivity in irritable bowel syndrome. Curr Gastroenterol Rep. 2011;13:308-15.

6. Tang QL, Lai ML, Zhong YF, Wang AM, Su JK, Zhang MQ. Antinociceptive effect of berberine on visceral hypersensitivity in rats. World J Gastroenterol. 2013;19:4582-9.

7. Klooker TK, Braak B, Koopman KE, Welting 0, Wouters MM, van der Heide $S$, et al. The mast cell stabiliser ketotifen decreases visceral hypersensitivity and improves intestinal symptoms in patients with irritable bowel syndrome. Gut. 2010;59:1213-21.

8. Ohman L, Simrén M. Pathogenesis of IBS: role of inflammation, immunity and neuroimmune interactions. Nat Rev Gastroenterol Hepatol. 2010;7:163-73.

9. Philpott H, Gibson P, Thien F. Irritable bowel syndrome - An inflammatory disease involving mast cells. Asia Pac Allergy. 2011;1:36-42.
10. Vanuytsel $\mathrm{T}$, van Wanrooy $\mathrm{S}$, Vanheel $\mathrm{H}$, Vanormelingen C, Verschueren S, Houben E, et al. Psychological stress and corticotropin-releasing hormone increase intestinal permeability in humans by a mast cell-dependent mechanism. Gut. 2014;63:1293-9.

11. Cukier JM, Cortina-Borja M, Brading AF. A case-control study to examine any association between idiopathic detrusor instability and gastrointestinal tract disorder, and between irritable bowel syndrome and urinary tract disorder. Br J Urol. 1997;79:865-78.

12. Guo YJ, Ho CH, Chen SC, Yang SS, Chiu HM, Huang KH. Lower urinary tract symptoms in women with irritable bowel syndrome. Int J Urol. 2010;17:175-81.

13. Francis CY, Duffy JN, Whorwell PJ, Morris J. High prevalence of irritable bowel syndrome in patients attending urological outpatient departments. Dig Dis Sci. 1997;42:404-7.

14. Monga AK, Marrero JM, Stanton SL, Lemieux MC, Maxwell JD. Is there na irritable bladder in the irritable bowel syndrome? Br J Obstet Gynaecol. 1997;104:1409-12.

15. Kaplan SA, Dmochowski R, Cash BD, Kopp ZS, Berriman SJ, Khullar V. Systematic review of the relationship between bladder and bowel function: implications for patient management. Int J Clin Pract. 2013;67:205-16.

16. Li ZS, Zhan LX, Zou DW, Xu GM, Man XH, Gong YF. Visceral hypersensitivity model induced by intraperitoneal injection of chicken egg albumin. Acad J Sec Mil Med Univ. 2003;24:127-30.

17. Al-Chaer ED, Kawasaki M, Pasricha PJ. A new model of chronic visceral hypersensitivity in adult rats induced by colon irritation during postnatal development. Gastroenterology. 2000;119:1276-85.

18. Zhang NZ, Ma L, Zhang JB, Chen J. Improved model for the establishment and evaluation of detrusor overactivity in female Wistar rats. Int Braz J Urol. 2014;40:414-21.

19. Elzayat E, Khaled S, Kashiwabara T, Elhilali M, Corcos J. Effect of the potassium channel opener WAY-133537 on the overactive bladder of spinalized rats. Neurourol Urodyn. 2006;25:808-14.

20. Lluel P, Duquenne C, Martin D. Experimental bladder instability following bladder outlet obstruction in the female rat. J Urol. 1998;160:2253-7.

21. Keszthelyi D, Troost FJ, Masclee AA. Irritable bowel syndrome: methods, mechanisms, and pathophysiology. Methods to assess visceral hypersensitivity in irritable bowel syndrome. Am J Physiol Gastrointest Liver Physiol. 2012;303:G141-54.

22. Gevaert T, De Vos R, Everaerts W, Libbrecht L, Van Der Aa $F$, van den Oord $J$, et al. Characterization of upper lamina propria interstitial cells in bladders from patients with neurogenic detrusor overactivity and bladder pain syndrome. J Cell Mol Med. 2011;15:2586-93. 
23. Steers WD. Pathophysiology of overactive bladder and urge urinary incontinence. Rev Urol. 2002;4 Suppl 4:S7-S18.

24. Letourneau R, Pang X, Sant GR, Theoharides TC. Intragranular activation of bladder mast cells and their association with nerve processes in interstitial cystitis. $\mathrm{Br} \mathrm{J}$ Urol. 1996;77:41-54.

25. Keith IM, Jin J, Saban R. Nerve-mast cell interaction in normal guinea pig urinary bladder. J Comp Neurol. 1995;363:28-36.

26. Chung SD, Liu HT, Lin H, Kuo HC. Elevation of serum c-reactive protein in patients with $\mathrm{OAB}$ and IC/BPS implies chronic inflammation in the urinary bladder.Neurourol Urodyn. 2011;30:417-20.

27. Liu HT, Chancellor MB, Kuo HC. Urinary nerve growth factor levels are elevated in patients with detrusor overactivity and decreased in responders to detrusor botulinum toxin-A injection. Eur Urol. 2009;56:700-6.

28. Liu HT, Tyagi P, Chancellor MB, Kuo HC. Urinary nerve growth factor but not prostaglandin E2 increases in patients with interstitial cystitis/bladder pain syndrome and detrusor overactivity. BJU Int. 2010;106:1681-5.
29. Liu HT, Shie JH, Chen SH, Wang YS, Kuo HC. Differences in mast cell infiltration, E-cadherin, and zonula occludens-1 expression between patients with overactive bladder and interstitial cystitis/bladder pain syndrome. Urology. 2012;80:225.e13-8.

30. Collington SJ, Williams TJ, Weller CL. Mechanisms underlying the localisation of mast cells in tissues. Trends Immunol. 2011;32:478-85.

31. Batler RA, Sengupta S, Forrestal SG, Schaeffer AJ, Klumpp DJ. Mast cell activation triggers a urothelial inflammatory response mediated by tumor necrosis factor-alpha. J Urol. 2002;168:819-25.

32. Birder LA. More than just a barrier: urothelium as a drug target for urinary bladder pain. Am J Physiol Renal Physiol. 2005;289:F489-95.

33. Gonzalez RR, Fong T, Belmar N, Saban M, Felsen D, Te A. Modulating bladder neuro-inflammation: RDP58, a novel anti-inflammatory peptide, decreases inflammation and nerve growth factor production in experimental cystitis. J Urol. 2005;173:630-4.

Correspondence address: Hui-qing Yuan, MD

Department of Biochemistry and Molecular Biology Shandong University School of Medicine 44\#, Wenhua Xi Road, Jinan, 250012, P.R. China Telephone: +860 531 8839-5114 E-mail: znz95znz@mail.sdu.edu.cn 